\title{
I.S.C.H. and LABORATOIRE L. LAFON
}

\section{HEMORHEOLOGY-MICROCIRCULATION AWARD}

\begin{abstract}
BACKGROUND: Laboratoire L. Lafon has provided funds for a HemorheologyMicrocirculation Award to recognize research activities relating the fields of hemorheology and microcirculation. This Award will be administered by the International Society for Clinical Haemorheology (I.S.C.H.), and will be presented at the 9th International Congress of Biorheology - 2nd International Conference on Clinical Hemorheology, July 23-28, 1995, Big Sky, Montana (USA).

AMOUNT: $\$ 2000$ (USA)

APPLICATION: Interested individuals are requested to submit two copies of either: 1) a peer-review paper published within the past three years or 2) an "in press" paper accepted for publication in a peer-review journal. In addition, the applicant should include a letter indicating the importance of the research to the areas of hemorheology and microcirculation. Note that only one application per paper is allowed.
\end{abstract}

SELECTION: $\quad$ The recipient of the Award will be selected by an International Advisory Committee representing experts in the fields of hemorheology and microcirculation.

DEADLINE: $\quad$ February 1, 1995

SEND TO: $\quad$ Dr. Herbert J. Meiselman

Department of Physiology and Biophysics

USC School of Medicine

2025 Zonal Avenue

Los Angeles, CA 90033 USA

(213) 342-1268 (phone)

(213) 342-2283 (FAX) 